\title{
EFFECT OF AERODYNAMIC MOMENT ON HIGH-SPEED MAGLEV TRAIN UNDER COMPLICATED CONDITIONS
}

\author{
Zhanzhou Hao \\ University of Chinese Academy of Sciences \\ Key Laboratory for Mechanics in \\ Fluid Solid Coupling Systems \\ Institute of Mechanics \\ Chinese Academy of Sciences \\ Beijing China \\ Email: haozhanzhou@imech.ac.cn \\ Guowei Yang \\ Key Laboratory for Mechanics in \\ Fluid Solid Coupling Systems \\ Institute of mechanics \\ Chinese academy of sciences \\ Beijing China \\ Email: gwyang@imech.ac.cn
}

\author{
Bo Yin* \\ Key Laboratory for Mechanics in \\ Fluid Solid Coupling Systems \\ Institute of mechanics \\ Chinese academy of sciences \\ Beijing China \\ Email: yinbo@imech.ac.cn
}

\author{
Pan Xiao \\ The State Key Laboratory of Nonlinear Mechanics \\ Institute of mechanics \\ Chinese academy of sciences \\ Beijing China \\ Email: xiaopan@Inm.imech.ac.cn
}

\section{ABSTRACT}

As the next generation of high-speed rail transportation, the high-speed maglev train has a design speed of $600 \mathrm{~km} / \mathrm{h}$, whose Mach number is about 0.49 . The severe aerodynamic effect caused by this high speed has a substantial impact on the train's stability and safety. In this paper, the aerodynamic moments of two three-carriage maglev trains passing by each other in open air are investigated by numerical simulation. To get transient moments acting on the train, this study adopted the sliding mesh method and the $k-\varepsilon$ turbulent model, and a user-defined function was compiled to define the motion of maglev. The results show that the pitching moment is the most important factor for the steady of maglev trains running in the open air. The oscillation of the total aerodynamic moment mainly comes from the moment acting on the lower part. The coupling of the pitching moment acting on the upper and lower part of carriages make the peak of the total pitching moment behind the total yawing moment.

\footnotetext{
*Address all correspondence to this author.
}

\section{INTRODUCTION}

As the next generation of high-speed rail transportation, the high-speed maglev trains have a design speed of $600 \mathrm{~km} / \mathrm{h}$, which is about twice that of the traditional high-speed trains. Compared with conventional trains [1-3], differences in construction make maglev trains have faster running speeds, lower maintenance costs, lower mechanical vibrations, and stronger environmental resistance [4]. With these features, a lot of countries, such as Germany, Japan South Korea, the U.S., and China, have developed maglev train technologies. Maglev technology can be divided into electromagnetic suspension(EMS) and electrodynamic suspension(EDS) in terms of levitation mechanism. The EMS devices lift the trains through the attraction generated by the electronically controlled electromagnets arranged on the bottom of the vehicle and the T-shaped track and rely on the linear motor to pull the trains. The EDS devices rely on the electromagnetic effect of the magnets arranged at the bottom of the train and the levitation coil installed on the rail to generate repulsive and attractive force to adjust the designed levitation position when the train is running at a certain speed [5].

Aerodynamic problems associated with the high-speed of maglev trains are receiving increasing attention as practical en- 


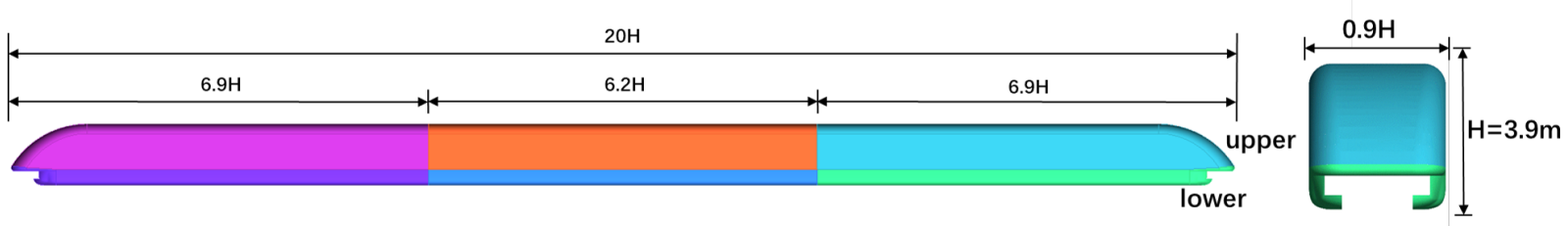

FIGURE 1. Geometrical Description Of Maglev Model
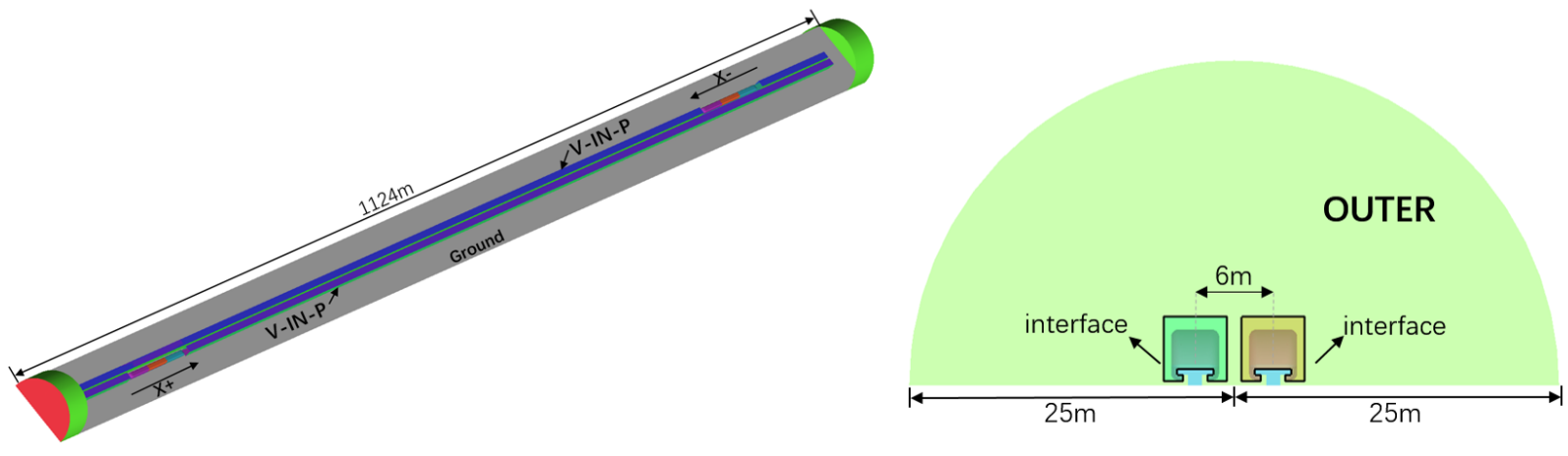

FIGURE 2. Computational Domain and Interface Definition

gineering issues that should be urgently resolved [6]. When the train moves at high speed in the air, its aerodynamic performance such as aerodynamic resistance, lift, and so on, is closely related to its aerodynamic shape [7]. The nose configuration of the leading and tail carriage has an important influence on the aerodynamic force of the train, increasing the length of the streamlined nose is one of the effective ways to decrease train aerodynamic drag [8]. However, different from the traditional highspeed train [9], the excessive aerodynamic lift is the key problem that restricts the development of maglev train. DING et al. [10] study the lift distribution laws of high-speed maglev trains with five carriages and the influencing factors. And a method of controlling train lift force by controlling the airflow in the air gap space is proposed. In addition, the dynamic effect caused by trains passing by each other is a more important factor affecting its safe operation. When the trains passing by each other, the spot which sustains the most pressure fluctuation is at the widest part of the vehicle [11], Sha Huang et al. [12] analyzed the transient pressure distribution and flow field distribution of the $430 \mathrm{kn} / \mathrm{h}$ maglev train, and concluded that the transient pressure generated inside the intersection of the two vehicles is about twice that of the outside, and a recommended value is proposed for the safe station distance of the magnetic levitation.

It is worth noting that most of the current studies only discuss the changes in the aerodynamic force of maglev trains over time [13] and wave phenomena [14], while few of them focus on the aerodynamic moment. The complicated flow field during the operation of the maglev train will greatly affect its safety and stability $[15,16]$. Therefore, in-depth research on the aerodynamic moment of the maglev train under adverse operating con- ditions [17-19]is necessary. In this paper, using the sliding mesh method, the aerodynamic moment acting on the three carriages of the maglev train is simulated by a three-dimensional numerical method, when the train passing by each other. The oscillation of the pitching moment is analyzed, as well as the coupling of the components of aerodynamic moment acting on the upper and lower part of each carriage.

\section{NUMERICAL METHOD Geometrical Model}

The train model in this study is a full-scale TR08 train with three carriages, which runs on the Shanghai maglev demonstration line. As shown in Fig 1, focusing on more efficient calculation, only the profile of the train body is retained, while the windows, magnets, and windshields are simplified. The height $\mathrm{H}$, regarded as the characteristic length of the train, is about $3.9 \mathrm{~m}$. The total length and width of the train are $20 \mathrm{H}$ and $0.9 \mathrm{H}$, respectively. The length of the head car(car1) and tail car(car3) are both $6.9 \mathrm{H}$, and the length of the middle car(car2) is $6.2 \mathrm{H}$. For analyzing the aerodynamic force and moment loaded on the train, each car is divided into two parts, upper and lower, one of which surrounding the track.

\section{Computational Domain and Boundary Conditions}

As shown in Fig2, in the case of two trains running in the open air, the total computational domain is divided into three parts: V-IN-P contains the train moving along the $\mathrm{x}+$ direction, $\mathrm{V}-\mathrm{IN}-\mathrm{N}$ contains the train moving along the $\mathrm{x}$ - direction, and the 
OUTER is the surrounding field of the moving domain. The initial distance between the nose of the two trains is about $728 \mathrm{~m}$, which ensure the flow field is fully developed when the train running steady and passing by each other in the open air. The shape of the OUTER is a semi-cylinder with a length of $1124 \mathrm{~m}$ and a radius of $25 \mathrm{~m}$. The boundary conditions of the two end faces and side faces are set to be pressure-outlet. The ground and track are set to be ground. The couple boundaries between V-IN-P(VIN-N) and OUTER are set to be interfaces where the relative motions and(or) data exchange occurring, shown with backline in Fig2. As the speed of the train is $600 \mathrm{~km} / \mathrm{h}$, the line space between tracks is set to $6 \mathrm{~m}$. Adopting the sliding mesh method, the motion of the maglev train consists of a smooth start phase and a uniform running phase.

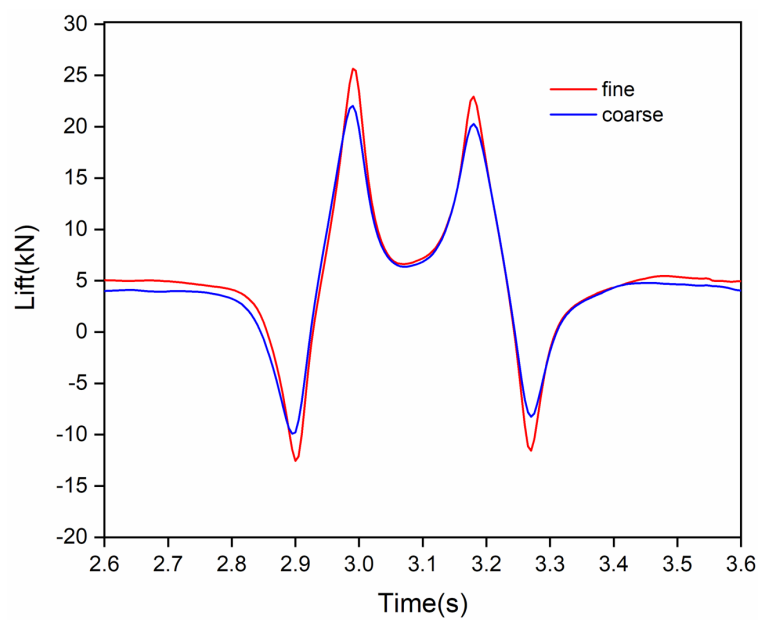

(a)

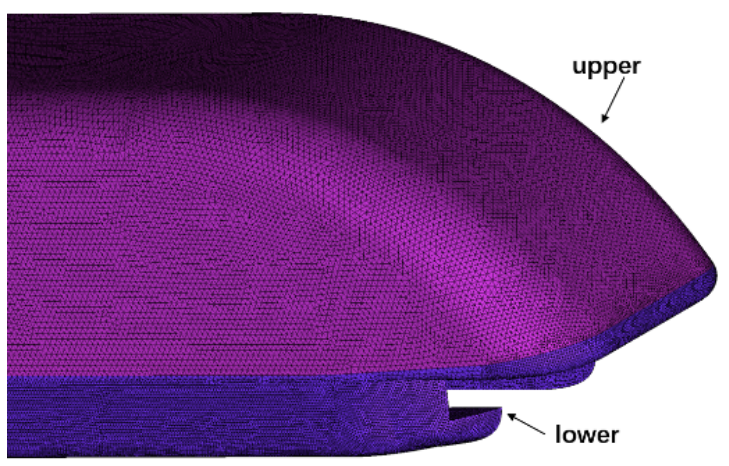

(b)

FIGURE 3. Computational Mesh and Independence Verification

\section{Solver Settings and Governing Equation}

The continuity equation, Reynolds-average Navier-Stokes (RANS) equations, and standard $k-\varepsilon$ model are are used in this study for the unsteady airflow. Since the highest train speed is about $600 \mathrm{~km} / \mathrm{h}$, with a corresponding Mach number (Ma) of about 0.5 , the airflow must be treat as compressible flow. The governing equations are discretized on finite-volumes. Therefore, a pressure-based compressible solver is adopted and the SIMPLE algorithm is applied to solve the pressure-velocity coupling equations. For spatial discretization, the gradients were computed using the Least Squares Cell-Based in the control volumes. The second-order upwind scheme is employed for the discretization of convection-diffusion terms. For unsteady analysis, a first-order implicit scheme was adopted. The physical time step is set as $0.004 \mathrm{~s}$ with 20 interactions in each time step, and a userdefined function was compiled to define the motion of maglev and monitor the transient aerodynamic moment. The $k$ - $\varepsilon$ turbulence model of the two equations can be expressed as follows:

$$
u_{j, j}=0
$$

$$
\rho u_{j} u_{i, j}=-P_{, i}+\left(\mu+\mu_{t}\right)\left(u_{i, j j}+u_{j, i j}\right)
$$

$$
\begin{gathered}
\rho u_{j} k_{, j}=\left[\mu+\frac{\mu_{t}}{\sigma_{k}}\right] k_{, j j}+\mu_{t} G_{k}-\rho \varepsilon \\
\rho u_{j} \varepsilon_{, j}=\left[\mu+\frac{\mu_{t}}{\sigma_{\varepsilon}}\right] \varepsilon_{, j j}+c_{1} \frac{\varepsilon}{k} \mu_{t} G_{k}-\rho c_{2} \frac{\varepsilon^{2}}{k}
\end{gathered}
$$

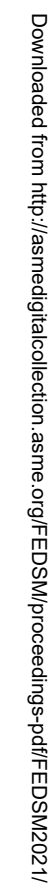

where $G_{k}=\left(u_{i, j}\right)^{2}+u_{i, j} u_{j, i} ; \mu_{t}=\rho c_{\mu} \frac{k^{2}}{\varepsilon} ; P$ and $\rho$ represent the aerodynamic pressure and the air density respectively; $\mu$ and $\mu_{t}$ represent the air dynamic viscosity and the eddy viscosity respectively; $k$ and $\varepsilon$ represent the turbulent kinetic energy and dissipation rate respectively; $c_{1}, c_{2}, c_{\mu}, \sigma_{k}$, and $\sigma_{\varepsilon}$ are constants with values of $1.44,1.92,0.09,1.0$ and 1.3 , respectively.

\section{Mesh Independence}

Representing a compromise between ease of use and accuracy, the unstructured hybrid mesh is adopted in this simulation. The mesh near the train is unstructured and refined at the bottom so that it can encounter the accurate simulation for the flow field and aerodynamic forces and moments. The structured mesh is generated far around the train, which can reduce the expense of calculation. To verify mesh independence, two sets of unstructured mesh are set up: a coarse mesh with 7,891,167 and a fine mesh with 13,280,011. As Fig3 (a) shown, the lift of the upper half of the middle car (car2) for the different mesh, when the train passing by each other, is compared. The trends of the two curves are basically the same, except for the values of peaks. The relative error of time average lift before passing for fine and coarse mesh are 0.01 . The mesh of the lower part of the carriage is refined due to the little gap between the train and track, as shown in Fig3 (b).

\section{VALIDATION}

To verify the reliability of the present CFD simulation, the numerical results were compared with the experience results carried out by [20].In his study, the aerodynamic pressure loads on 
the maglev vehicle, whose speed is $500 \mathrm{~km} / \mathrm{h}$, was investigated in Shanghai in November 2003. Five points were set on the leading car to measure the pressure load on the train surface when the train passes a standing train (Standing Passing) and passes another moving train (Flying passing). The line space of the track is $5.1 \mathrm{~m}$. They provided the average pressure loading on the monitoring points. In the meantime, the train-induced airflow speeds were also measured at two positions, $0.5 \mathrm{~m}$, and $1.3 \mathrm{~m}$, away from the passing vehicle side.In this study, one of the monitoring points was selected for verification. As shown in Table 1 , the characteristic value of the pressure at a monitor point during the train passing by each other was compared. $\Delta \mathrm{P} \_\mathrm{L}$ is the amplitude of the leading pressure wave, $\Delta \mathrm{P}_{-} \mathrm{T}$ is the amplitude of the tailing pressure wave, and pass_P is the pressure value of the train running between the leading wave and the tailing wave. The Relative error of $\Delta \mathrm{P}_{-} \mathrm{L}, \Delta \mathrm{P}_{-} \mathrm{T}$, and pass_P is $0.016,0.038$ and 0.009 . The numerical results can correctly reflect the changes of aerodynamic force and aerodynamic moment during train operation.

TABLE 1. Comparisons of the characteristic values between experiment and numerical simulation

\begin{tabular}{clll}
\hline Method & $\Delta \mathrm{P}_{-} \mathrm{L}(\mathrm{Pa})$ & $\Delta \mathrm{P}_{-} \mathrm{T}(\mathrm{Pa})$ & pass_P(Pa) \\
\hline Experiment & 4757 & 3955 & 324 \\
Simulation & 4834 & 3804 & 330 \\
\hline Relative error & 0.016 & 0.038 & 0.009 \\
\hline
\end{tabular}

TABLE 2. Mean value of aerodynamic moment before passing by each other

\begin{tabular}{clll}
\hline mean value $(\mathrm{kN} \cdot \mathrm{m})$ & car1 & car2 & car3 \\
\hline rolling moment & -1.84 & 0.29 & 0.33 \\
pitching moment & -143.01 & 3.65 & 1392.65 \\
yawing moment & -19.11 & 0.07 & -4.84 \\
\hline
\end{tabular}

TABLE 3. Mean value of pitching moment for each part of carriages before passing by each other

\begin{tabular}{clll}
\hline pitching moment $(\mathrm{kN} \cdot \mathrm{m})$ & car1 & car2 & car3 \\
\hline upper & -736.17 & -0.52 & 936.67 \\
lower & 593.16 & 4.17 & 455.99 \\
total & -143.01 & 3.65 & 1392.65 \\
\hline
\end{tabular}
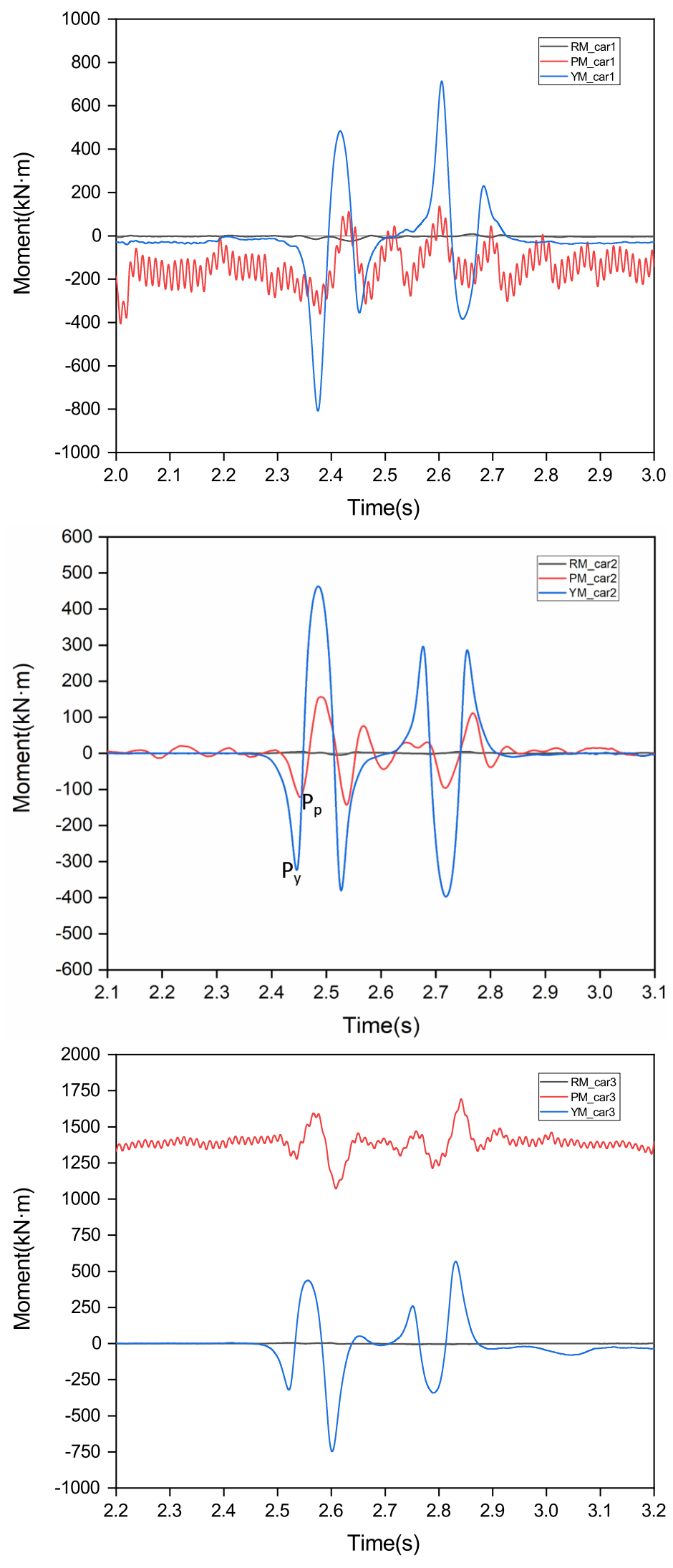

FIGURE 4. Aerodynamic Moment Curves of Each Carriage 


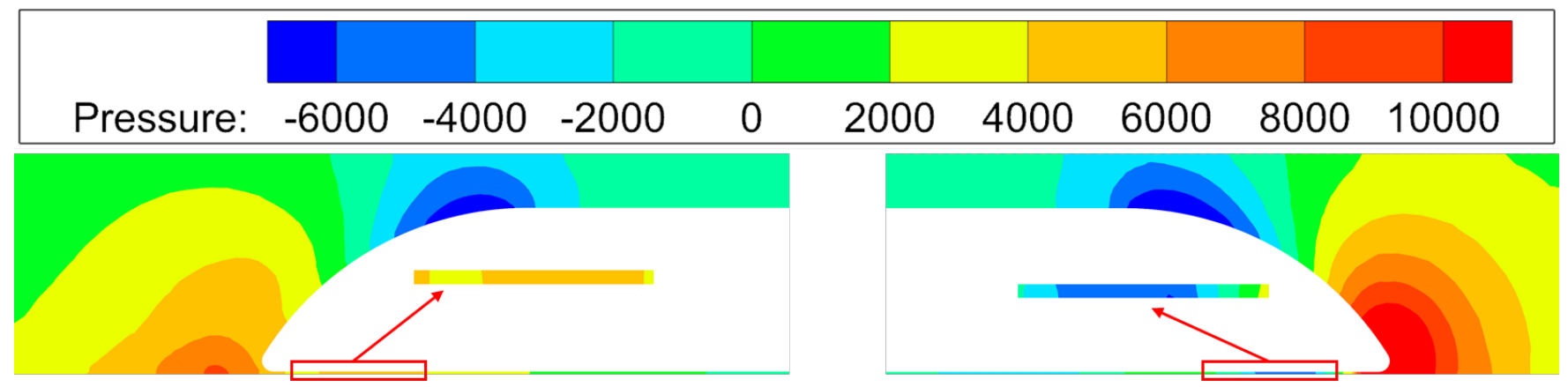

FIGURE 5. Pressure around car1(right) and car3(left)

\section{RESULTS AND DISCUSSION}

\section{Aerodynamic Moment Distribution}

In order to get the realistic effect of the aerodynamic moment loaded on the train, the points for calculating moments are the real mass centroid of each carriage, not the figure centroid of the intersecting surface. The centroids are $1.32 \mathrm{~m}$ higher than the upper surface of the track and at the middle of the width of the train. The longitudinal position of the centroids is at the middle of the carriage for car2, and about $24.38 \mathrm{~m}$ away from the car2 centroid for car1 and car3, respectively.

The curves of the rolling moment, pitching moment, and yawing moment, loaded on the three carriages are shown in Fig 4. Clearly show, the pitching moments of car1 and car3 oscillate violently in the whole process, while the rolling moment and yawing moment, because of the symmetrical construction of the carriages, both have a near-zero value and smooth curve before the intersection. This shows that the pitching moment seriously affects the stability of train operation, which is worthy of attention. The mean values of them before passing by each other are shown in Table 2. Focus on the pitching moment, the value of car 1 is about $-143 \mathrm{kN} \cdot \mathrm{m}$, which will make car 1 raise its nose, and the value of car3 is $1392 \mathrm{kN} \cdot \mathrm{m}$, which makes car3 rise its nose much more serious. To analyze the reasons for this significant difference, the mean value of pitching moment for each part of carriages is shown in Table 3 and the pressure around the car 1 and car3 is shown in Fig 5. Clearly show, there are two negative pressure areas around the upper part of car1 and car3 that rise the carriages. Below car1, there is another negative pressure area that makes the train close to the track. Under the reverse coupling of two negative pressure areas, the pitching moment of the head car is small. However, below the car3, there is a positive pressure which also raises the nose of car3, just like the negative area on the upper part. Because of the positive coupling of the two pitching moments acting on the upper and lower part of car3, the total pitching moment of car3 is about 9.5 times that of car1. When the train passing by each other, the pitching and yawing moment change significantly. The largest amplitude of these moments for different carriages lists in Table 3. It shows that, for the rolling and yawing moment, the values of car 1 change largest, and for the pitching moment, the value of car3 changes largest. It is worth noting that the largest amplitude of yawing moment for each carriage is about 2.5 times the pitching moment, as shown in Table 3. Another noteworthy thing is that as the points Pp and Py demonstrate, the peak of the pitching moment curve seems always behind the peak of yawing moment curve. The time difference is about $0.001 \mathrm{~s}$.

TABLE 4. Largest amplitude of aerodynamic moment when passing by each other

\begin{tabular}{clll}
\hline largest amplitude $(\mathrm{kN} \cdot \mathrm{m})$ & car1 & car2 & car3 \\
\hline rolling moment & 25.73 & 8.22 & 9.39 \\
pitching moment & 506.38 & 302.80 & 550.05 \\
yawing moment & 1314.60 & 836.67 & 972.06 \\
\hline
\end{tabular}

\section{The Source Of Oscillation And Time Difference}

As mention above, the pitching moment shows obvious oscillation in the whole process, especially for car1 and car3, which is different from the smooth results from [18]. To find the reason, we split the train model into two parts, upper and lower, as shown in Fig 1. The pitching moments of the different parts of each carriage are shown in Fig 6. Be easy to see, the black lines have the same vibration frequency with the red lines, which represent the pitching moment loaded on the total carriage and the lower part, respectively. The curves for the upper parts are relatively smooth, corresponding to the blue lines. And the mean value of the lower part is larger than that of the upper part. That means the pitching moment acting on the lower part plays a major role in the total moment, especially for the oscillation. In addition, the car1's pitching moment value of the upper part (PM_car1_u) is positive, which lowers the nose, and the lower part(PM_car1_l) is negative, which upper the nose. The coupling of them reduces the total value of the pitching moment. For car3, the pitching moment of different parts is both positive, which aggravates the instability of it.

Notice the green and gray lines in Fig 6, the peaks for the pitching moment of the upper and lower parts are always on the green line. The peaks for that of total carriages are always on the gray lines. That is due to the reverse coupling of the upper part and lower part, which have different change rates. For the 
yawing moment, as shown in Fig 7, the two parts have a positive coupling, making the three peaks of yawing moments on the same line. All of these make the peak of the total pitching moment curve always behind that of the total yawing moment curve.

\section{CONCLUSION}

The aerodynamic moment of maglev trains before and during passing by each other was investigated, using the sliding mesh method. The moment distribution of different parts carriages and the source of moment oscillation were analyzed, as well as the moment coupling of different parts. From the present numerical study, some observations are drawn as follow: 1. When the maglev train operating in the open air, the pitching moment of car1 and car3 seriously affects the stability of the train. The pitching moment value of the tail car is about 9 times of the leading car. 2. The moment of the lower part plays a major role in the total moment mean value. The oscillation of the aerodynamic moment is mainly due to the gap flow between the train and track, which makes the moment of the lower part of carriages unsteady. 3. During the maglev train passing by each other, the yawing moment changes most significantly, of which the largest amplitude is about 2.5 times that of pitching moment. Due to the reverse coupling of the pitching moment acting on the upper and lower part, the peak of the total pitching moment is always $0.01 \mathrm{~s}$ behind that of the total yawing moment for each carriage.
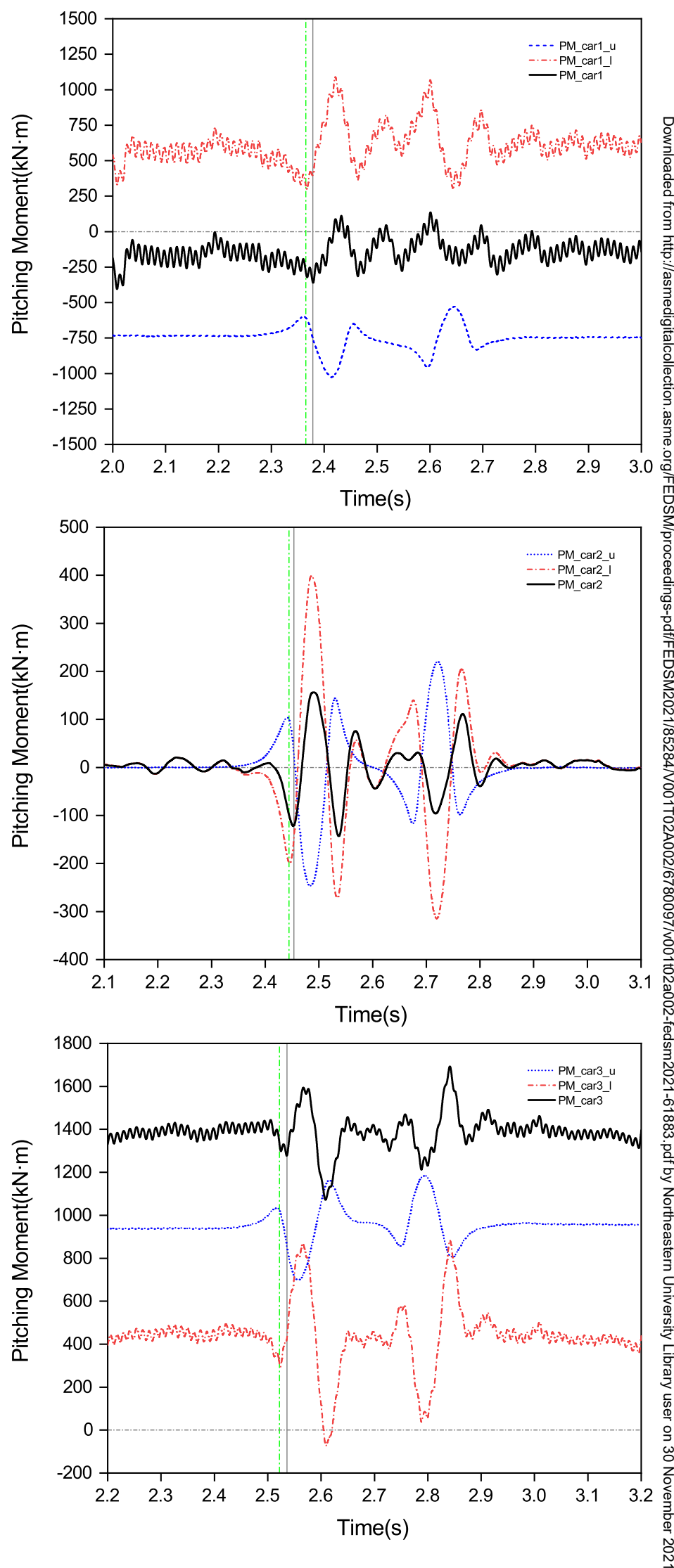

FIGURE 6. Pitching Moment of Upper and Lower Part for Each Carriage 

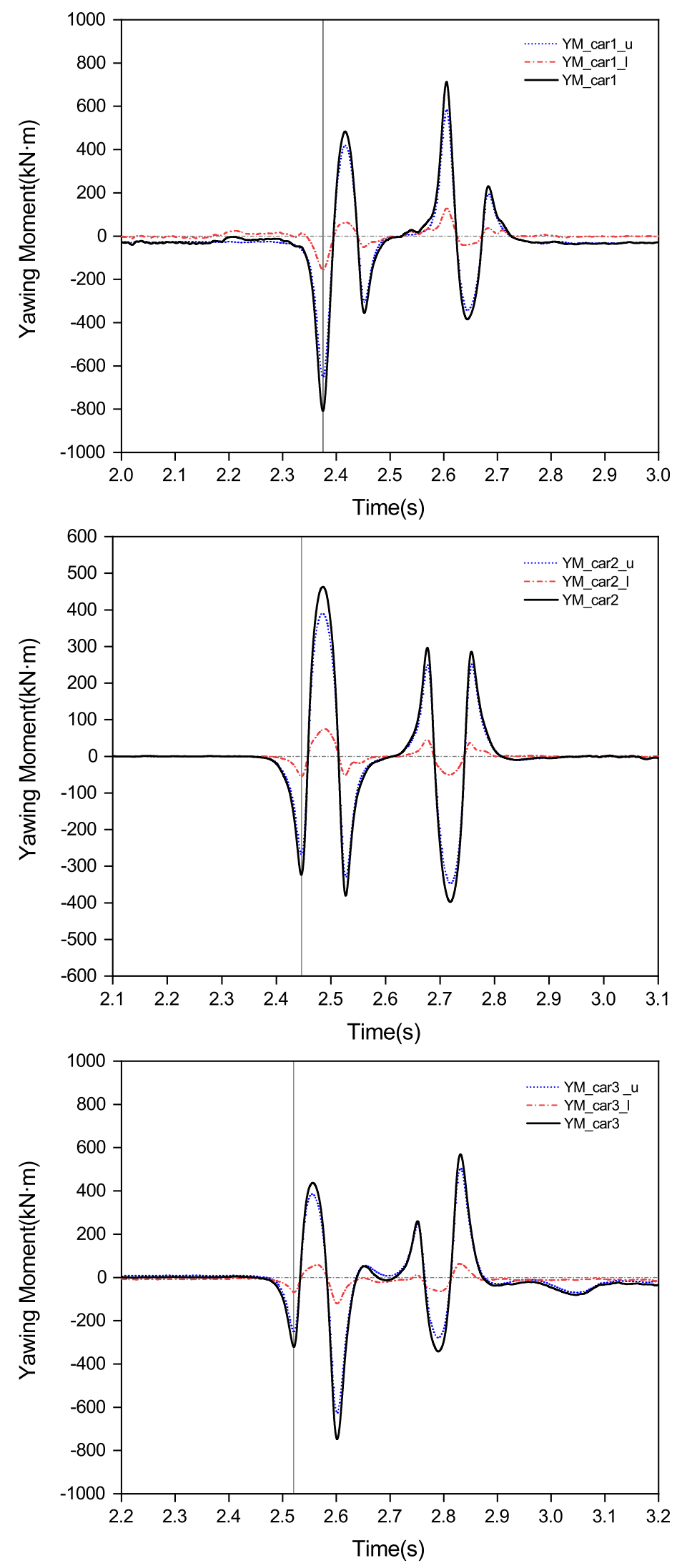

FIGURE 7. Yawing Moment of Upper and Lower Part for Each Carriage

\section{ACKNOWLEDGMENT}

This work is supported by the National Key Research and Development Program of China (2016YFB1200602), the Informatization Plan of the Chinese Academy of Sciences (XXH13506-204) and Strategic Priority Research Program of the Chinese Academy of Sciences (XDB22020101).

\section{REFERENCES}

[1] Fujii, K., and Ogawa, T., 1995. "Aerodynamics of highspeed trains passing by each other". Computers \& Fluids, 24(8), pp. 897-906.

[2] Schetz, J. A., 2001. "Aerodynamics of high-speed trains". Annual Review of Fluid Mechanics, 33, pp. 371-414.

[3] Ivanov, N. I., Boiko, I. S., and Shashurin, A. E., 2017. "The problem of high-speed railway noise prediction and reduction". Procedia Engineering, 189, pp. 539-546.

[4] Raghunathan, R. S., Kim, H. D., and Setoguchi, T., 2002. "Aerodynamics of high-speed railway train". Progress in Aerospace Sciences, 38(6-7), pp. 469-514.

[5] Lee, H. W., Kim, K. C., and Lee, J., 2006. "Review of maglev train technologies". Ieee Transactions on Magnetics, 42(7), pp. 1917-1925.

[6] Yau, J. D., 2010. “Aerodynamic vibrations of a maglev vehicle running on flexible guideways under oncoming wind actions". Journal of Sound and Vibration, 329(10), pp. 1743-1759.

[7] Sun, Z., Yao, Y., and Yang, G., 2021. "Research progress in aerodynamic optimization of high-speed trains". Chinese Journal of Theoretical and Applied Mechanics, 53, p. 24.

[8] Shu, x., gang, G. C., feng, L. X., and Chuang, G., 2006. "Numerical simulation and parameterized investigation of aerodynamic drag performances of high-speed maglev trains". Journal of $T$ raffic and Transportation Engineering, 6(2), p. 5.

[9] YAO, S., Guo, D., and Yang, G., 2012. "Distribution of high-speed train aerodynamic drag". JOURNAL OF THE CHINA RAILWAY SOCIETY, 34, pp. 6-23.

[10] Ding, S., Yao, S., and Chen, D., 2020. "Aerodynamic lift force of high-speed maglev train". Journal of Mechanical Engineering, 56(8).

[11] Gao, D. G., Ni, F., Lin, G. B., Luo, S. H., and Ji, W., 2019. "Aerodynamic analysis of pressure wave of high-speed maglev vehicle crossing: Modeling and calculation". Energies, 12(19).

[12] Huang, S., Li, Z., and Yang, M., 2019. "Aerodynamics of high-speed maglev trains passing each other in open air". Journal of Wind Engineering and Industrial Aerodynamics, 188, pp. 151-160.

[13] Zhou, P., Li, T., Zhao, C. F., and Zhang, J. Y., 2020. "Numerical study on the flow field characteristics of the new high-speed maglev train in open air". Journal of Zhejiang University-Science A, 21(5), pp. 366-381.

[14] Zhou, P., Zhang, J., Li, T., and Zhang, W., 2019. "Numerical study on wave phenomena produced by the super high-speed evacuated tube maglev train”. Journal of Wind Engineering and Industrial Aerodynamics, 190, pp. 61-70. 
[15] Wang, H. D., Deng, Z. G., Ma, S. S., Sun, R. X., Li, H. T., and Li, J. P., 2019. "Dynamic simulation of the hts maglev vehicle-bridge coupled system based on levitation force experiment". Ieee Transactions on Applied Superconductivity, 29(5).

[16] Liu, W., and Guo, W. H., 2020. "Vibration analysis of emstype maglev vehicles traveling over a long-span bridge with double lines". Ksce Journal of Civil Engineering.

[17] Kwon, S.-D., Lee, J.-S., Moon, J.-W., and Kim, M.-Y., 2008. "Dynamic interaction analysis of urban transit maglev vehicle and guideway suspension bridge subjected to gusty wind". Engineering Structures, 30(12), pp. 34453456.

[18] Huang, z., 2018. "Study on aerodynamics of super high speed maglev train". Thesis, Southwest Jiaotong University.

[19] Zhai, M. D., Long, Z. A., and Li, X. L., 2019. "A new strategy for improving the tracking performance of magnetic levitation system in maglev train". Symmetry-Basel, 11(8).

[20] Li, M., and LEEI, B., 2006. "Field measurement of passing pressure and train induced airflow speed on high speed maglev vehicles". ACTA AERODYNAMIC SINICA, 24(02581825( 2006) 02-0209-04), p. 4. 